\title{
Buildings Façades A Challenge of Cultural Identity In The Context Of Modernity
}

\author{
Dr. Imad M. Assali \\ Assistant Professor / Chairperson of Interior Design Department, College of Arts, Science \& Education, Ahlia \\ University, Kingdom of Bahrain, email: iassali@ahlia.edu.bh
}

\begin{abstract}
The Industrial Revolution in 1798, which accompanied with the European colonization, the discovery of oil, and globalization introduced new design guidelines for building facade. As a result, facade design which used to be a cultural issue in traditional architecture based on adaptation to environmental conditions of using local materials loses connection to their contextual surroundings which concentrate on an extensive use of glass which ignore privacy, comfortable thermal conditions that increase energy consumption, and a poor day lighting performance ${ }^{1}$. In addition, building façades in the whole world look very similar which do not offer any specific characters responding to country, area, and/or building location that resulted from uncomfortable indoor environment ${ }^{2}$. As A result, a crisis of architectural identity emerged as a result of the phenomenon of globalization, which causes building users to be uncomfortable in the indoor environment. At this point, a critical question is raised; to what extent the architectural identity of a façade design could be influenced by the adoption of modern design trends? This question represents the main research question that the paper will address. This research identifies the modern technologies that influence the architectural identity of building façade; it also seeks to answer the key question how the traditional elements of the facades are reflected in the contemporary works. It also aims to examine how traditional façade can be used as a base for developing and modernizing the building's façade without just blindly imitating and repeating the past. Therefore, the main concept is reaching a new façade design that is responsive to the environmental contexts without affecting the continuity of architectural identity that maintain human comfort, reducing depending on active system, maintain privacy, saving energy, providing light, ventilation, noise control. Finally, this research focuses on the utilization of technology as an essential element toward progress in search of architectural identity.
\end{abstract}

Keywords: façade, architectural identity, Contemporary Architecture, globalization, modernity.
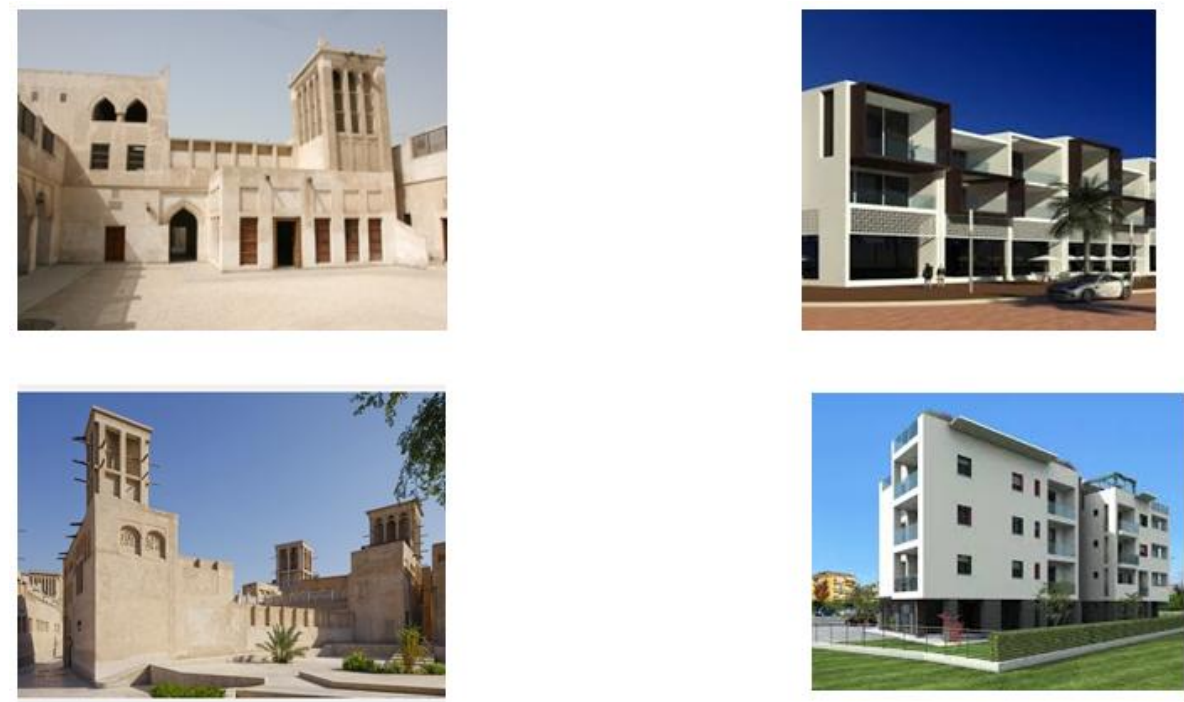

\footnotetext{
${ }^{1}$ Please see the photos in figure 1.

${ }^{2}$ Please see the photos in figure 2.
} 

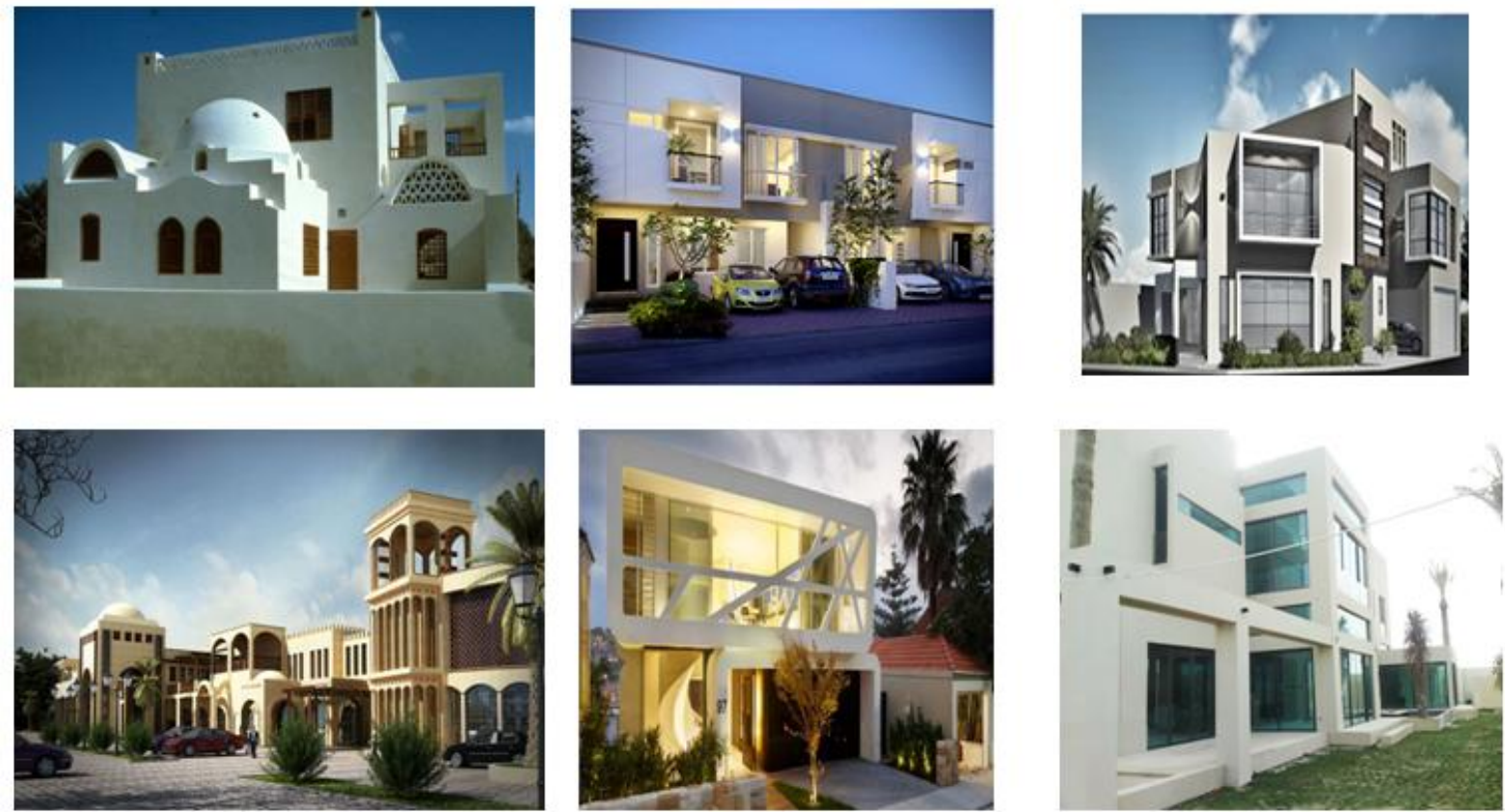

Figure 1: Traditional Facades VS Modern Building Facades (Source: the author).
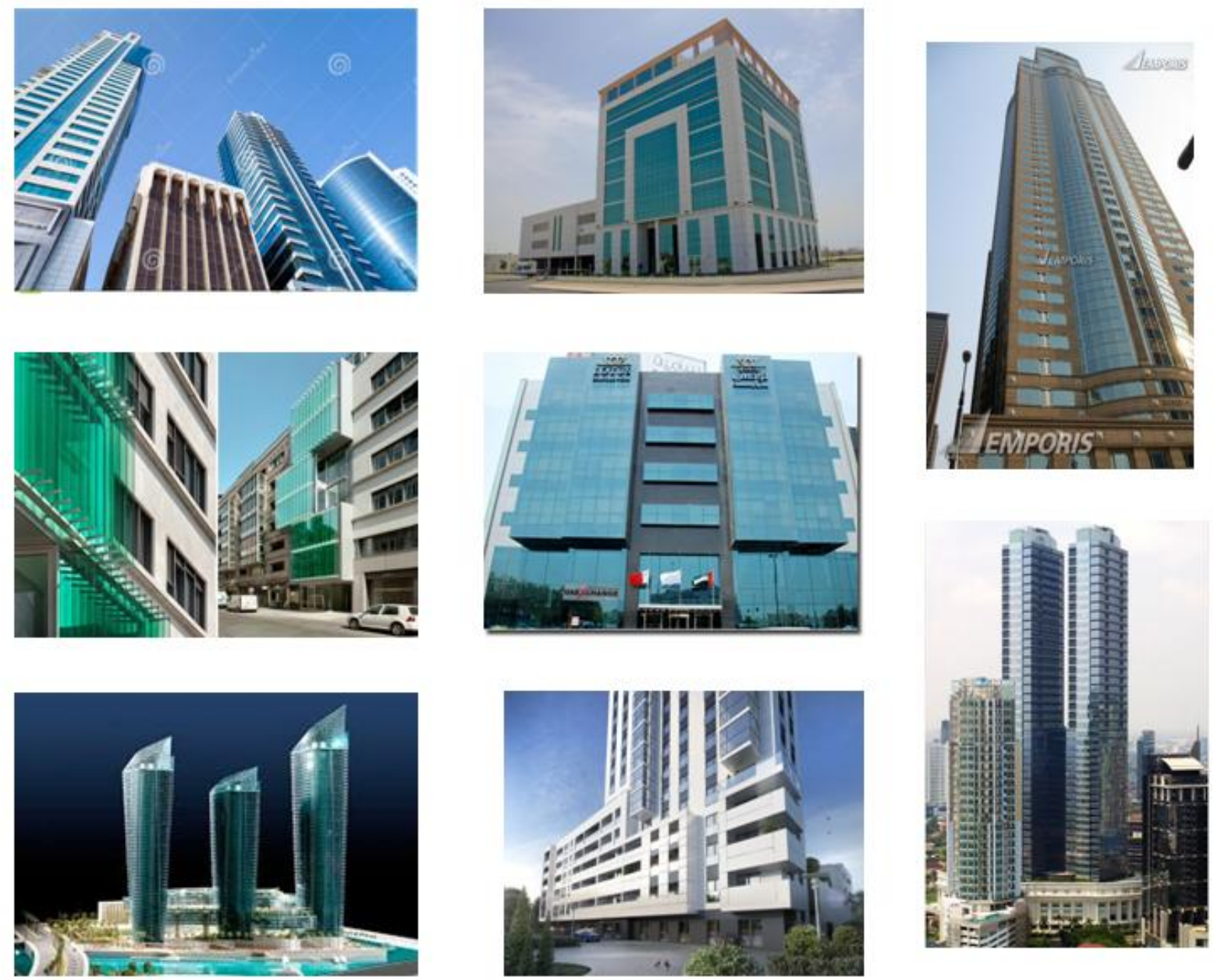

Figure 2: Illustrations show Building Facades in different countries (Source: the author) 


\section{Introduction}

"Authenticity in architecture means investigating and studying the architectural values of the past and then takes advantage of their lessons without copying the models" "[1] $]^{3}$ Façade is the first connection between humans and the built environment which determine the identity and symbolism of a building. In addition, it connects and separates the inner space to and from the environment that contain decorative elements, shapes, and patterns that express aesthetic, culture and the most noticeable place to illustrate beliefs [2]. Nowadays, the adoption of modern technologies in facade design is accompanied by discussions of the architectural identity. Therefore, a big debate between scholars is about modernity as a powerful force and its influences on architectural identity [3]. Identity does not mean the absolute adoption of the traditional model. It includes implications and lessons for the present and the past [1]. They call for understanding the values of the traditional architecture and learning from its experiments a source of inspiration rather than copying its elements. This research attempts to identify the elements used in contemporary building façade in relation to traditional architecture due to the variation of appearance and arrangement in order to satisfy both aesthetic aspects and optimizing their response and performance to the exterior environment [4]. Also, it will investigate if the design of building facades using modern technology will make a building more responsive to different environmental needs.

\section{A. Research Problem}

The main research problem is that building façades and the city image in Arab regions lose its architectural identity with innovations introduced by new technology introduced by architects and designer by importing styles from Europe and US to produce modernity which resulted from different building façades with different architectural languages which has no relation to the local environment.

B. Research Aim \& Objectives

The research main aim is to conserve the architectural identity in building façade as a result of the invasion of the western culture by setting guidelines and policies for design for contemporary architecture with regard to the potential of traditional innovations in modern architecture.

\section{Literature Review}

Historically, the traditional façade design relies on a passive design process in reducing both harmful emissions in the atmosphere and energy consumption [5]. This part will review the relevant literature to identify factors affecting the architectural identity represented by a building façade. A cultural heritage represented by a building architecture transmitted from one generation to the next one makes societies spends great efforts to conserve their building heritage [6]. They added the imported building styles in most of the Arab World is because people saw the traditional methods as a symbol of poverty and retardation, while the implementation of Western methods are the perfect evidence of civilization. On the contrary, an overuse of new technologies without considering the architectural heritage and local environment of a country increase the use of artificial devices in the interior of buildings to create occupants comfort $[7,8]$. Therefore, architecture requires blending modernity in terms of technological advancements and tradition in term of recognizing environmental and historical aesthetic elements of the region.

In fact, different reasons influenced the architectural identity of cities resulted from the emergence of new styles and movements define new cultural personas. The imported urban design practices and the municipal ordinances by local architects educated in Western Countries and international architects who experienced different architectural trends of widening existing streets to give primacy to the automobile resulted from demolition of parts of the traditional fabric of cities [9]. In addition, the use of innovative building technologies and materials represented by the widespread use of steel, concrete, and glass which considered signs of progress and development in the city and signs of prestige producing a crisis of architectural identity $[10,1]$. Furthermore, after the collapse of the Ottoman Empire and the establishment of national governments such as Jordan, Egypt, Syria, and Palestine under the British and the French Mandate, which later get its liberation. These colonized powers during their stay built new districts inhabited by Europeans and local elites influenced the traditional architecture by an exotic facade, albeit people in these countries viewing modernization as a gift from Europe [11].

\footnotetext{
${ }^{3}$ Abdelsalam T. \& Rihan G. M. (2012) "The impact of sustainability trends in housing design identity of Arab cities", Housing and Building National Research Center HBRC Journal, ONLINE: http://ees.elsevier.com/hbrcj, $\mathrm{P}: 163$
} 
In addition, the economic development in Arab Countries combined with the rapid population growth due to natural increase as well as rural-to-urban migration in addition to overpopulated cities' downtowns forced residents to abandoned these crowded areas and made them interested in brand new lifestyles away from the old centers, hence, created the need for numerous commercial projects and residential projects, new building typologies of multi-family housing, public, educational, sports, civic, and cultural buildings with facades seemingly based on Western influences that rejected traditional ornamentation and architectural vocabulary.

Besides, the involvement of international construction firms also resulted in the import of modern architectural forms and shapes from the western world led to a dynamic change in the skyline and overall cityscape through the construction of countless new towers and urban complexes of making a modern image of the city. However, numerous examples are witnesses to this claim, such as Water Towers in Kuwait, Alexandria Library.

\section{A. Identity and Modernity}

Architecture is a human mentality product past, present and future, which distinguishing of architecture product between communities. In practice, the notions of identity of a society are addressed through its architecture and its adaptation to environmental conditions that satisfy both the aesthetic and efficiency of building space. Furthermore, with the rise of modernism in architecture as a result of globalization and colonial powers, building facades have some details introduced to represent by construction techniques, material, and some ornamental elements which influence the architectural identity [11]. Hence, architectural identity may be modernized according to the circumstance of cultural changes [12]. In addition, architectural identity implied a place with a special characteristic that has a power of expression through a specific time, which differentiate between multiple societies, therefore, forgetting traditional architecture and using only modern technology would lead to forgetting the lessons that can be learnt from the history [6,13]. As a result, traditional architecture is a type of architecture that has historical and cultural continuity that has grown over time and adapting to the different social and economic conditions of each period, while, modernity is seen as a technological and scientific revolution that change the culture and social life and rejects the heritage of the past [14]. In addition, modernity is historical transformation aims to use new technology in order to provide sustainable buildings that respond to local environment and provide occupant satisfaction [15]. Hence, modern design is not a style it is a solution to modern problems, as new construction techniques allow for climate and environmental control [11]. Moreover, the change in architectural identity follows these categories. The first one is imitating the source without any modifications; the second with minor changes; the third adding new elements; the fourth one is a major change; the last one with totally changes that altering the system [14]. Several research studies about architectural identity and modernity in Kuwait by interviewing different architects. The study revealed that some architects use elements of traditional buildings of Kuwait to express architectural identity, while other architects believe to use new technologies that respond to the climatic conditions, people needs and the modernity of Kuwait [15].

\section{B. Transformation in Buildings Facades}

Façades are an outer skin of buildings produced from the arrangement of roof, openings which provide visual continuity with outdoor spaces, materials, finishes, building orientation, shading devices, and religious aspects like privacy. The façade of a building is an interaction of building and environment required for the particular function which should be in harmony between solid and transparent components, texture, solid and void, material, and color. Hence, building façade as visual elements in reference to both internal structure and external outline that gives unity to the whole Hence, these visual elements are: Line, shape, Color, and texture, while the principles combine these elements are: Axis, symmetry, repetition, hierarchy, rhythm, proportion, and scale [16]. Nowadays, the use of industrialized technology introduced in the building sector; the expression of economic power; and the manipulation of the construction material introduce different design styles for façade [17]. Technology has a great impact on architecture, but if the modern technology is used without cultural, social, and environmental aspects it will have a negative effect [16]. The contrast and number of elements measure the visual richness of building facades. Consequently, different visual problem affects the facade characteristic identity, sustainability, and aesthetic sense negatively. These can be summarized in the following [18]:

- Different styles which change the visual content totally.

- The building owner or tenant changes building appearance by simply painting it with unusual pigments; adding a new storey or part of users to an existing building or shading elements that may cover a vast percentage of the facade area, if not all of it.

- Reshaping facades by users by adding new architectural elements, details, paintings, and modern building services as providing natural ventilation and lighting. 
- Advertisements and banners have their strongest effect due to their various positions, sizes, shapes and directions (figure 3).
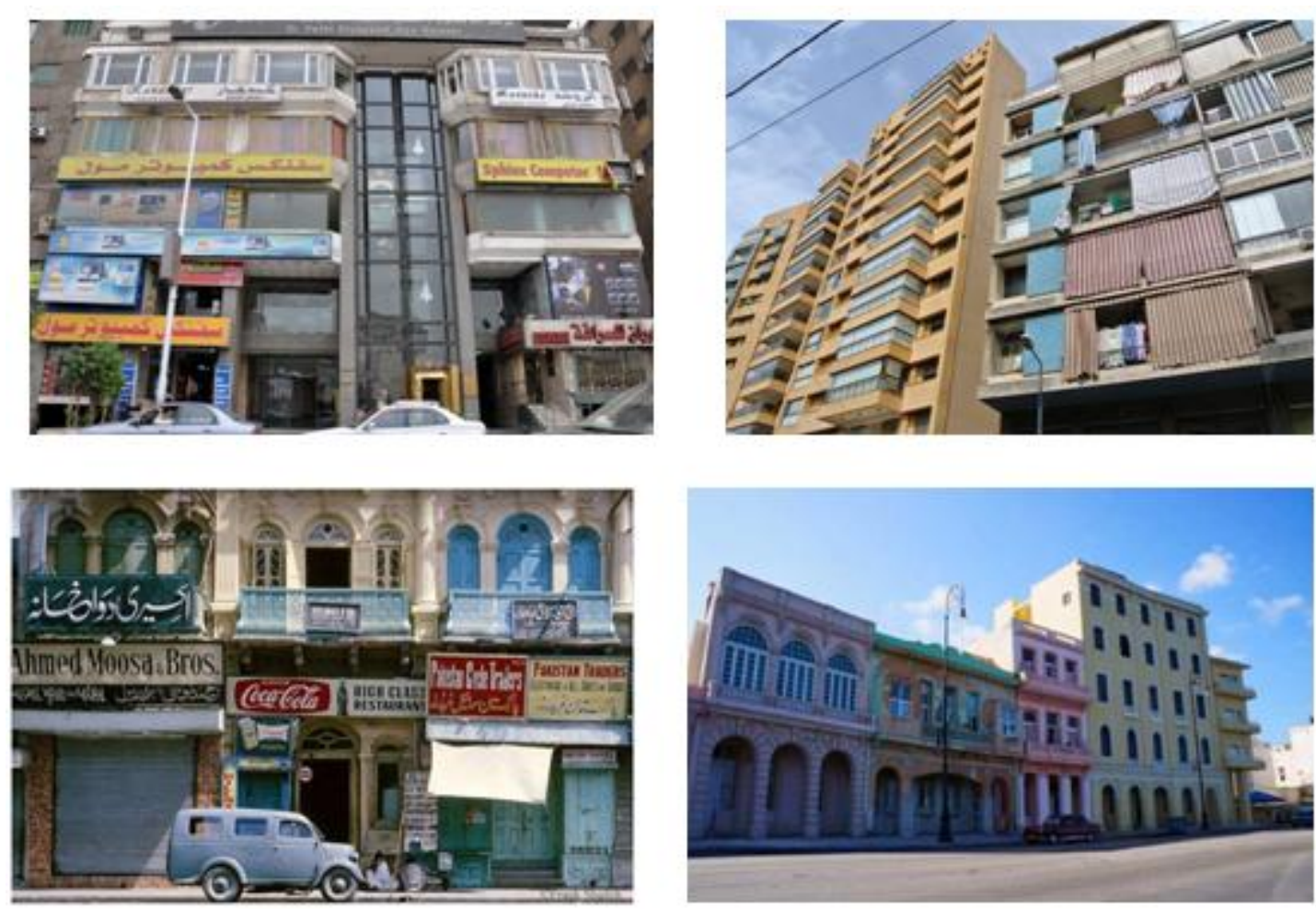

Figure 3: Illustrations show visual pollution in Building Facades (Source: the author).

\section{Technological Trend in Facade Design}

Nowadays, various technologies have exposed many changes in architectural design especially façade design. These technologies should express the traditional approach in dealing with environmental and aesthetic aspects that satisfy the local conditions to create an appropriate architectural identity [1]. They added these technologies should be revised and modified to take what is applicable in terms of its appropriateness for the social, cultural context, and environmental aspects. The Turkish architectural historian Doğan Kuban looked at the use of the western technology without giving appropriate attention to the local conditions at the positive side and acknowledges, "the mass of knowledge which comes from the west cannot be ignored, nor its impact be neglected. But this does not mean that we have to be subservient to the bigotry and cliché of modern jargon" " . Figure 4 shows the modern interpretation of a traditional "Mashrabiya" (carved wooden screen) which relies on new materials and form while keeping its concept.

${ }^{4}$ Abdelsalam T. \& Rihan G. M. (2012) "The impact of sustainability trends in housing design identity of Arab cities", Housing and Building National Research Center HBRC Journal, ONLINE: http://ees.elsevier.com/hbrcj, P 162. 

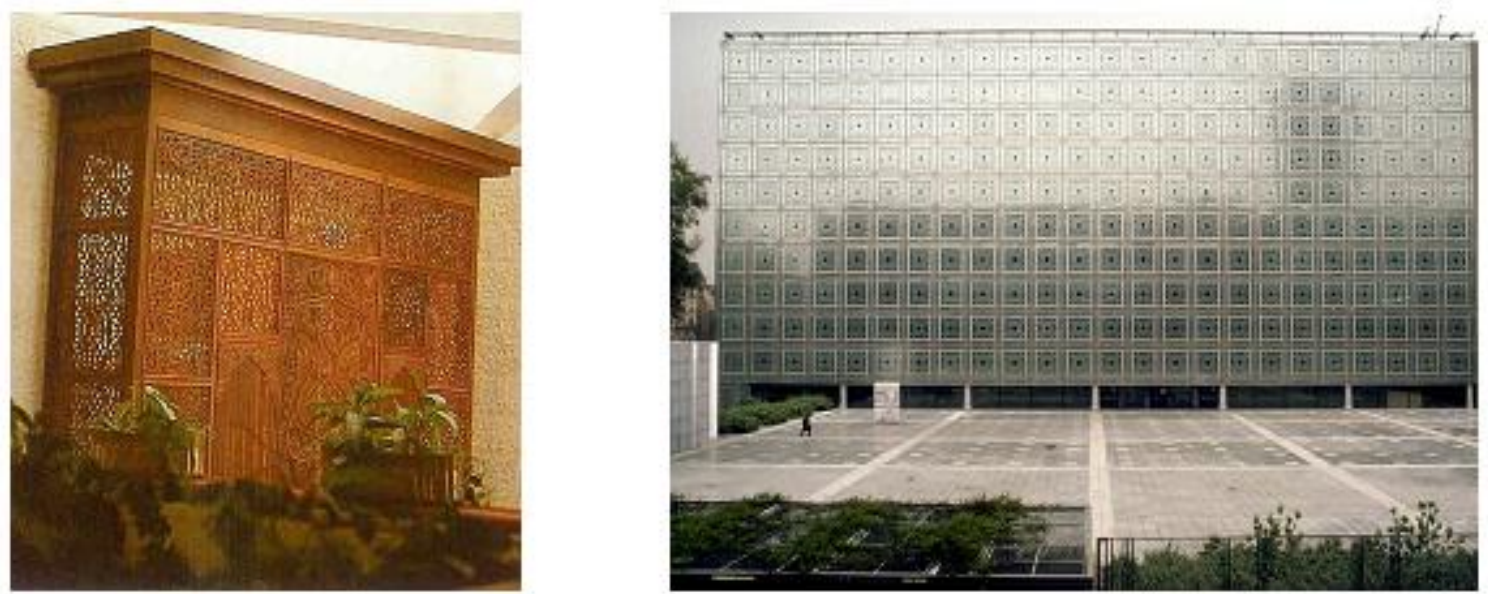

Figs. 4: Modern interpretation of traditional Elements.

Among these technologies used nowadays by architects and designers for facades is kinetic façade.

- Kinetic facades

Historically, the use of dynamic kinetic facades using automated louvers and adjustable overhangs has been adopted since 1960 as a response to environmental influences that make a building more sustainable to thermal, lighting, and ventilation issues and reduce the need for active system. As a result, kinetic façade design provides designers with effective feedback and the ability to test and simulate how a particular design performs under a range of conditions that are hardly to examine in previous time [19,5] (figure 5).
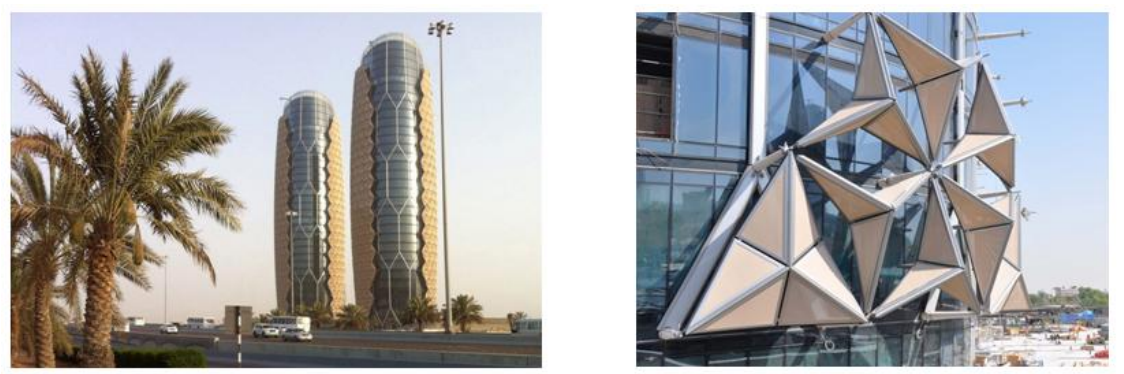

Figs. 5: The Al-Bahr Towers Abu Dhabi designed by AEDAS (Source: the author).

On good example is Al-Bahr Towers in Abu Dhabi, which was influenced by the traditional fort Al-Jahili in AlAin in UAE shown in Figure 6. The brief outline of the project "The building should reflect its prestigious status, contribute to the surrounding environment and take into account the architectural heritage of the UAE and Abu Dhabi in particular. A contemporary building utilizing modern technology is required, which should be recognized as one of the landmarks associated with the city of Abu Dhabi." [20] $]^{5}$.

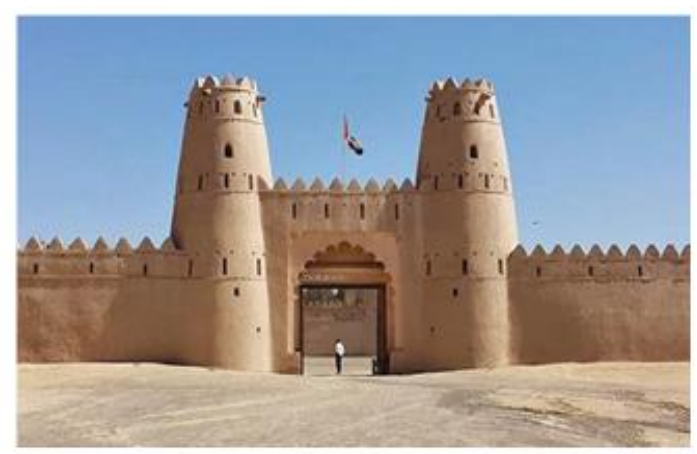

Figs. 6: The Al-Jahili Fort demonstrates local building traditions (Source: the author).

\footnotetext{
5 Abdelsalam T. \& Rihan G. M. (2012) "The impact of sustainability trends in housing design identity of Arab cities", Housing and Building National Research Center HBRC Journal, ONLINE: http://ees.elsevier.com/hbrcj, P 162.
} 


\section{Research Method}

This research attempts to examine the influences of modern technologies on buildings façades in the Arab cities and its impact on architectural identity. Therefore, the research method adopted were:

- Review some literatures about architectural identity and modernity ending up with an identification of architectural identity principles that influence the emergence of modern style trends in facade design in the Arab city.

- The research then presents the role of nostalgia in reviving architectural identity through discussing different elements in traditional architecture façade through some projects to explore the impact of these trends on the architectural identity of façade design.

\section{A. Hajj Terminal in Jeddah}

\section{Case Studies}

One of the most successful buildings erected in hot climates is the Hajj Terminal in the Kingdom of Saudi Arabia designed by Skidmore; Owings \& Merrill designed for the influx of religious pilgrims that stream into Saudi Arabia each year for the annual Hajj pilgrimage to Mecca. It is constructed in the shape of the modern tent roof allude the tent of nomadic tribes residing in the deserts of Arabia (figure 7). The lead designer Fazlur R. Khan stated that in order to transform the traditional tent form into modern functional space art technologies became essential. He added "This tent does not copy tents of the past - it is a form of the future, and here it will cater for today's needs - air travel." [21]".
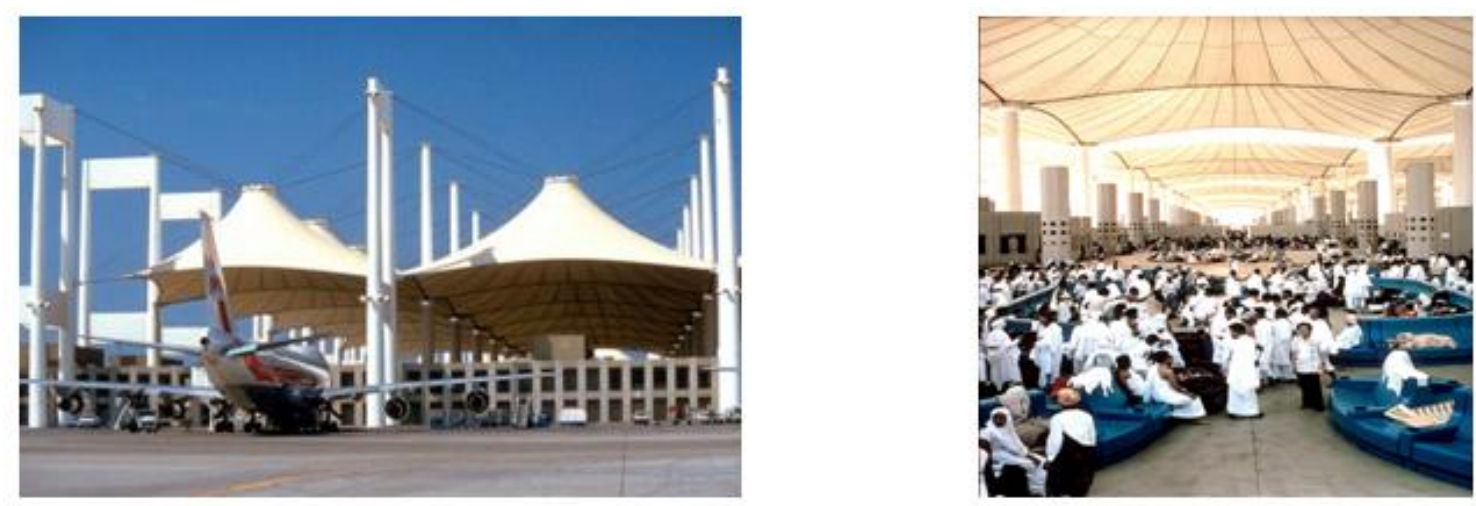

Figs. 7: The Hajj Terminal, Saudi Arabia (Source: the author).

The simple canvas and rope of a traditional tent were replaced by a massive Teflon-coated fiberglass fabric, steel pylons, and cables, therefore; the spirit of a tent in the desert was never lost. In addition, the structure provides the visitor with a spatial environment similar to that of traditional tent structures, and yet the design is far from traditional. The new material used reflects 76 percent of the solar radiation, maintaining a comfortable temperature under the tent structure and allows sunlight to pass through the tent which provides a comfortable illumination during daylight hours. The terminal consists of ten big modules; each one is made up of forty five square meters with twenty one units, while the tents are made up of steel rings with the high suspending cables from one module to another. After the project completion in 1981 received an AIA National Award. Finally, Hajj Terminal is an example of how a symbol of place may be adapted to a new context of application within the same culture.

\section{B. Marsa Dubai Residential Tower}

The Marsa Tower project shows the influence of digital technology on its façades, designed by Zaha Hadid (figure 8). The openings on the exterior façade used traditional Islamic motifs arranged from small geometric shapes at the tower's base to a larger size at the top of the tower to increase the structural efficiency. The openings in each façade were designed to combine both environmental and aesthetic aspects that reduce reliance on artificial systems.

\footnotetext{
$\overline{{ }^{5}}$ Alhasani N. M. (1996) " Tradition vs. Modernity: The Quest for a Cultural Identity", TDSR Vol. VII No. 1, P: 38.
} 

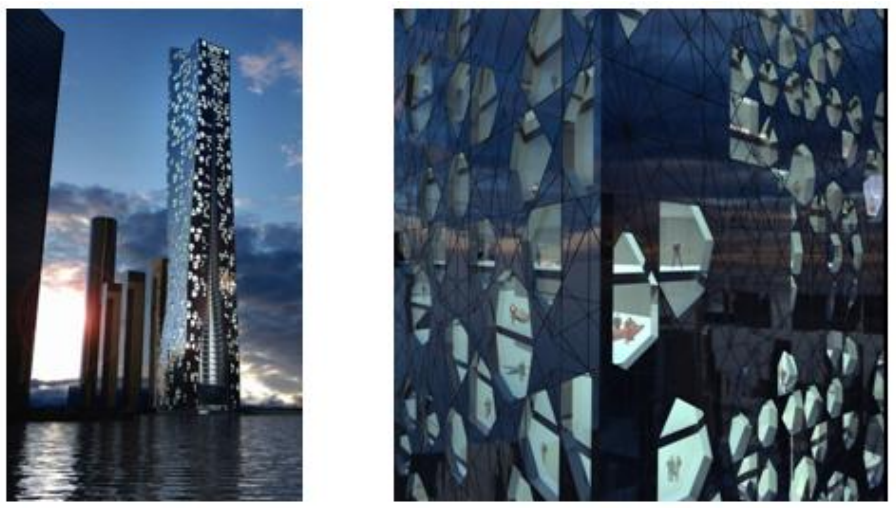

Figs. 8: Marsa Dubai Residential Tower (Source: the author).

\section{Private Projects (Villa)}

In general, architects design the individual residential buildings in Arab countries to satisfy their owners desires and needs which is influenced by religious and cultural backgrounds. Usually, these architects are related to different regions whose concepts of architectural heritage of the country are different [15]. The result is different residential buildings in different architectural style with no relation to its architectural heritage (Figure 9).
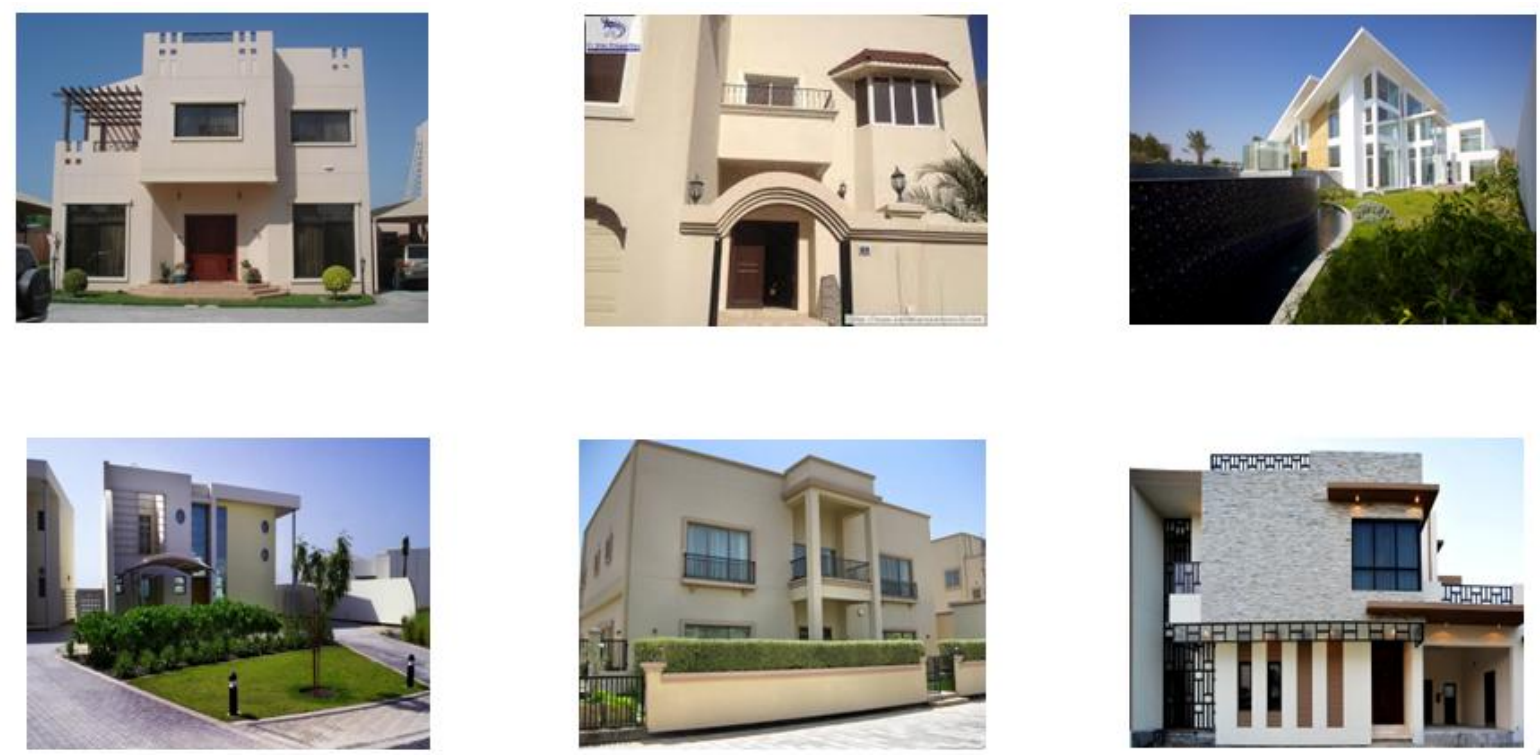

Figs. 9: Private Residential Buildings Facades (Villas) (Source: the author).

\section{Al Makkiyah Residential Villa Jeddah, Saudi Arabia ${ }^{6}$}

Almakkiyah is a residence designed by Sami M Angawi which combines modern construction techniques with traditional Islamic architectural heritage reflected by the use of internal courtyard, 'Mashrabiya', the vaulted roof, and the use of local building materials are all features which encourage privacy and enhancing the quality of the internal micro-climate naturally which are elements of passive design (fig. 10).

6 Al-Makkiyah Residential Villa, Aga Khan Award for Architecture, 2007 Award Cycle, online: file:///F:/FACADE/Makkya\%20residence\%20Jedda.pdf 

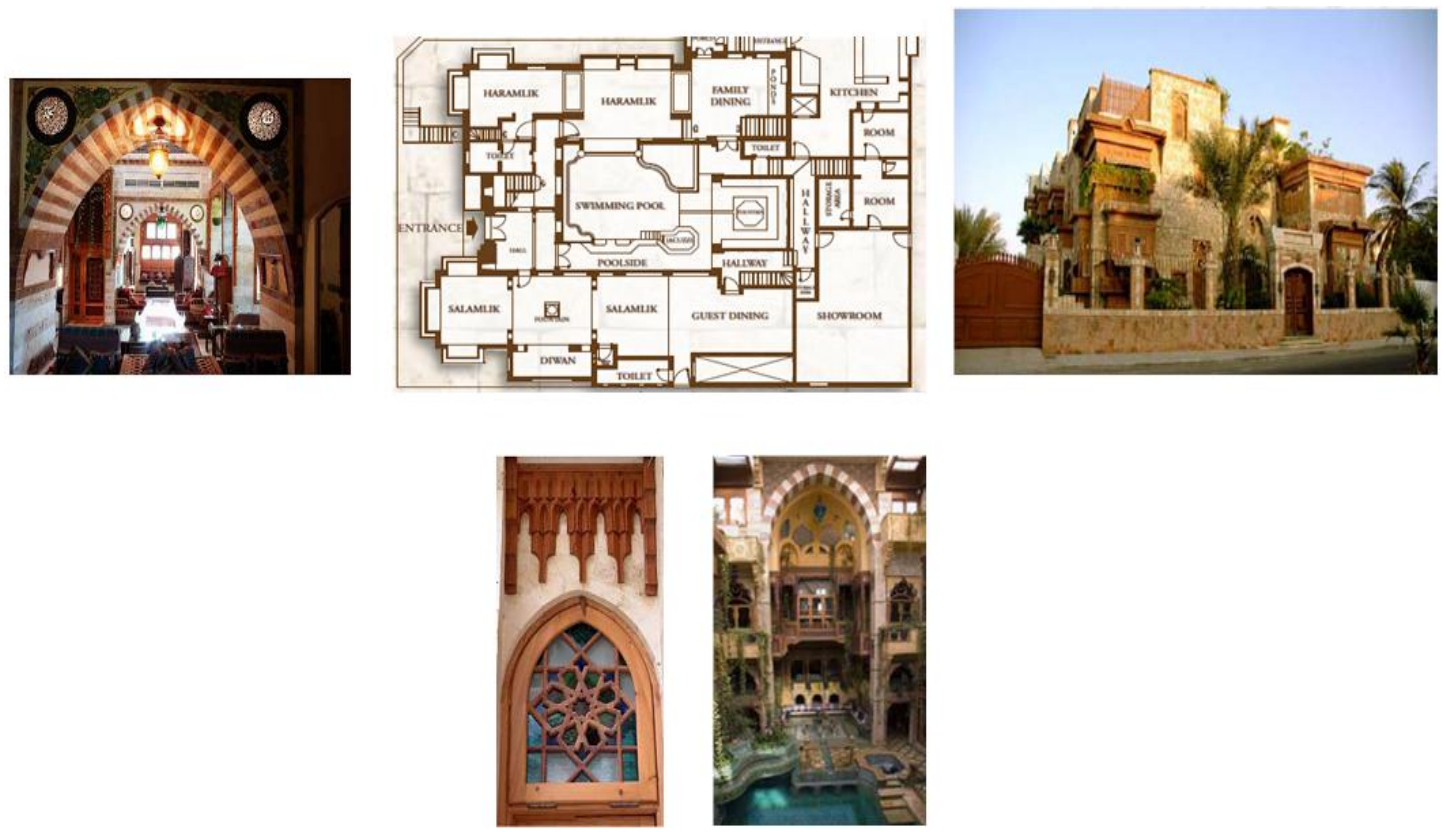

Figure 10: Al Makkkiyah Residence (Source: Aga Khan Award for Architecture, 2007 Award Cycle).

\section{Conclusion}

The previous analysis of case studies concerning the building facades using modern technology introduces successful solutions at the environmental level not only on a small scale but also on large scale and high rise commercial buildings. In addition, each case study has been clarified building façade role to achieve identity and modernity and better environmental quality in terms of natural ventilation, shading techniques and energy conservation and its role in enhancing the internal environment.Thus, the success or failure of reconciling architectural identity and technology is not a function of what to implement, but rather how to implement it in a given context to be incorporated into building facades and applied everywhere to attain the same success at both the environmental and identity level of the local community. On the contrary, the absolute adoption of the traditional solutions introduces cultural identity without any integration with the modernity nowadays. Finally, architects, planners, and urban designers should consider important issues that affect on the technologies applied into building facades such as cost, site, climatic conditions (Abedi \& Soltanzadeh, 2014). Finally, the finding of this research concludes that modern technologies should consolidate the continuity of architectural identity on building facades.

\section{References}

[1] Abdelsalam T. \& Rihan G. M. (2012) "The impact of sustainability trends on housing design identity of Arab cities", Housing and Building National Research Center HBRC Journal, ONLINE: http://ees.elsevier.com/hbrcj

[2] Ekhlassi A. \& Rafati A. (2015), "Facade Tectonics in Traditional Houses of Shiraz, Iran, Case Study: Zinat-al-Molk House", Armanshahr Architecture \& Urban Development, 7 (14), 37-48, Spring Summer 2015 ISSN: 2008-5079.

[3] AL-SHWANI S.Y.B. (2011), "INFLUENCE OF MODERNITY VERSUS CONTINUITY OF ARCHITECTURAL IDENTITY ON HOUSE FACADE IN ERBIL CITY, IRAQ", PhD Thesis UNIVERSITI SAINS MALAYSIA.

[4] Elghazi Y., Wagdy A., Mohamed S., Hassan A. (2014), " DAYLIGHTING DRIVEN DESIGN: OPTIMIZING KALEIDOCYCLE FACADE FOR HOT ARID CLIMATE", Fifth German-Austrian IBPSA Conference RWTH Aachen University.

[5] Kensek K. \& Hansanuwat R. (2011), " Environmental Control Systems for Sustainable Design: A Methodology for Testing, Simulating and Comparing Kinetic Facade Systems", Journal of Creative Sustainable Architecture \& Built Environment, CSABE Vol. 1, Novermber, 2011.

[6] Abedi M. \& Soltanzadeh H. (2014), "The Interaction between Tradition and Modernity in Contemporary Architecture of Persian Gulf States: Case Study of United Arab Emirates", International Journal of Research in Humanities and Social Studies Volume 1, Issue 1, November 2014, PP 24-34.

[7] Sendi M. (2014), "The Effect of Technology to Integrate Aesthetic Desire of Contemporary Architecture with Environmental Principles in Façade Design", International Scientific Journal Architecture and Engineering, Vol.2, Issue 1, online: http://architecture.scientific-journal.com

[8] Yadav, R., Sarkar, J., and Jadhav, K.K.P (2014), "Design Thought: Innovative façade design strategies", https://www.coa.gov.in/show_img.php?fid=178

[9] Elshahed M. (2007), "Facades of Modernity Image, Performance, and Transformation in the Egyptian Metropolis", MSc Thesis in Architecture Studies, MASSACHUSETTS INSTITUTE OF TECHNOLOGY.

[10] JULAIHI W. \& KHOZAEI F. (2008) "VISUAL PRIVACY AND RESIDENTIAL FACADES IN TRADITIONAL AND MODERN HOUSES, CASE STUDY: HOUSES IN HOT-ARID REGION OF IRAN", 5th great Asian streets symposium.

[11] Pilder A.D. (2011), "URBANIZATION AND IDENTITY: THE BUILDING OF AMMAN IN THE TWENTIETH CENTURY", Master of Arts Thesis, Department of History, Faculty of Miami University. 
[12] Correa, C. (1983), "Quest for Identity. In: Architecture and Identity", Powell, R. (Ed.). Aga Khan Award for Architecture, Singapore, pp: $10-14$.

[13] Colquhoun A. (1985), "Essays in Architectural Criticism: Modern Architecture and Historical Change". 1st Edn., The MIT Press, Cambridge, ISBN: 13: 9780262530637, pp: 223.

[14] Baper S.Y. \& Hassan A.S. (2010), "The Influence of Modernity on Kurdish Architectural Identity", American Journal of Engineering and Applied Sciences 3 (3): 552-559, 2010 ISSN 1941-7020.

[15] Ibelings H. (1998), "Super modernism: Architecture in the Age of Globalization", 1st Edn., NAI Publishers, USA., ISBN: 9056620746, pp: 144.

[15] Mahgoub, Y. (2007), "Hyper Identity: The Case of Kuwaiti Architecture," in ArchNet-IJAR: International Journal of Architectural Research, Vol. 1 (2007).

[16] Sabah O.A. \& Binti Abdul Samad M.M.H. (2016), "PENANG/ GEORGETOWN'S SHOPHOUSE FACADE AND VISUAL PROBLEMS, ANALYTIC STUDY", Proceeding of 4th International Conference on Liberal Arts and Social Sciences 2016 (ICOLASS'16).

[17] AKŞIT S. F. (2010), "Designing opaque building façade components for cooling energy conservation", Istanbul Technical University Faculty of Architecture, Istanbul, TURKEY- ITU, VOL: 7 NO: 1 71-86 2010-1.

[18] Moughtin C., Taner O., Tiesdell S. (1999), "Urban Design: Ornament and Decoration" (Second Ed.). Oxford: Architectural Press.

[19] Sharaidin K. (2014), "Kinetic Facades: Towards design for Environmental Performance", Ph.D Thesis, School of Architecture and Design RMIT University.

[20] Karanouha, A. \& Kerbe, E. (2015), "Innovations in dynamic architecture The Al-Bahr Towers Design and delivery of complex facades", Journal of Facade Design and Engineering 3 (2015) 185-221 DOI 10.3233/FDE-150040 IOS Press.

[21] Alhasani N. M. (1996) " Tradition vs. Modernity: The Quest for a Cultural Identity", TDSR Vol. VII No. 1. 